\title{
Change in Femoral Neck Anteversion Relative to the Retrocondylar Coordinate System and Computed Tomography Axial Plane
}

\author{
Norio Imai $^{1}$, Dai Miyasaka ${ }^{2}$, Shinya Ibuchi ${ }^{3}$, Hayato Suzuki $^{4}$, Ken Suda ${ }^{5}$, Naoto Endo ${ }^{6}$ \\ ${ }^{1}$ Division of Comprehensive Geriatrics in Community, Niigata University Graduate School Medical and Dental Science, Niigata, Japan \\ 2, 3, 4, 5, ${ }^{6}$ Division of Orthopaedic Surgery, Niigata University Graduate School Medical and Dental Science, Niigata, Japan
}

\begin{abstract}
In the present study, we aimed to verify the discrepancies in the measured femoral neck anteversion (FNA) values relative to the retrocondylar plane and computed tomography plane by using computer simulation. We observed that the measured FNA values increased with an increase of each degree of extension and adduction. Moreover, in cases where the neck shaft angle was larger, the measured FNA values tended to increase more. The maximum discrepancy between the true value and measured value was $15.8^{\circ}$, whereas the largest difference between the maximum discrepancy and minimum discrepancy of the fixed neck shaft angle and FNA was $25.8^{\circ}$. In cases where the femur has a high neck shaft angle (valgus hip) and/or high anteversion, it is likely that the measured value is smaller than the actual value. Hence, it is essential to carefully consider the discrepancy of the measured value when the FNA is measured from the CT axial plane without any correction according to the retrocondylar plane.
\end{abstract}

Keywords: femoral neck anteversion, neck shaft angle, retrocondylar plane, computer simulation, discrepancy

\section{Introduction}

Femoral neck anteversion (FNA) is usually measured during the planning for stem anteversion prior to total hip arthroplasty (THA), the evaluation of stem anteversion after THA, and planning for valgus osteotomy with derotation. Hence, the accurate measurement of the FNA is vital [1]. To ensure such accurate measurements, it is preferred that FNA is measured using a standard coordinate system [2].

The retrocondylar plane [3], also termed as the table top plane [4], includes the most posterior point of the medial femoral condyle and lateral condyle, as well as the most posterior points of the greater trochanter of the femur. It is often used as a reference plane for the measurement of FNA $[2,3,5,6]$. Furthermore, FNA is also measured using the axial plane on computed tomography (CT), without any adjustment with the retrocondylar plane $[7,8,9]$. However, the discrepancy in the measured FNA values between the retrocondylar plane and CT axial plane has not been verified thus far.

In the present study, we aimed to verify the discrepancy in the measured FNA values between the retrocondylar plane and CT axial plane by using computer simulation.

\section{Materials and Methods}

Subject

This study was approved by the institutional review board of Niigata University Medical and Dental Hospital. We used the CT scan of a 38-year-old woman who presented to our institution for the evaluation of femoroacetabular impingement. She did not have any abnormalities of the lumbar spine; in particular, no evidence of spondylolisthesis or spondylosis was observed. The acetabula and femoral heads on both sides appeared normal on anteroposterior and lateral radiographs. A pelvic model was reconstructed with the ZedHip system ${ }^{\circledR}$ (Lexi, Tokyo, Japan), and was used for the three-dimensional assessment of lower extremity alignment, as described previously $[10,11,12]$.

Definition of the coordinate system of the femur A three-dimensional bone model was established by one of the authors (NI) using CT scan images of the femur with the patient in the supine position. The coordinate system was created using this bone model, according to the following definitions. The coordinate system of the femur comprised the retrocondylar plane and the femoral axis projected on the retrocondylar plane, and was created using the discrete points of the bone model. The retrocondylar plane included the most posterior points of the medial femoral condyle and the lateral femoral condyle, as well as the most posterior points of the greater trochanter of the femur. The femoral axis was identified as a line between the knee center and the trochanteric fossa. The unit vector of the femoral coordinate system was defined as follows: the $\mathrm{X}$ axis was perpendicular to the retrocondylar plane, the Y axis was the line on which the femoral axis was projected on the retrocondylar plane, and the $\mathrm{Z}$ axis was perpendicular to the $\mathrm{X}$ and $\mathrm{Y}$ axes. The axial plane was defined as the plane containing the $\mathrm{X}$ axis and $\mathrm{Z}$ axis, the coronal plane was defined as the plane containing the $\mathrm{X}$ axis and $\mathrm{Y}$ axis, and the sagittal plane was defined the plane containing $\mathrm{Y}$ axis and $\mathrm{Z}$ axis.

Definition of the femoral neck axis

Based on previous reports of the measurement of the neck shaft angle of the femur [2,13,14], we considered the following 3 neck shaft angles: $110^{\circ}$ as varus femur, $125^{\circ}$ as normal femur, and $140^{\circ}$ as valgus femur. Moreover, the FNA was measured for each femur with a different neck shaft angle, and hence, a total of $9(3 \times 3)$ three-dimensional femoral morphological models with different femoral neck axes were established. 


\section{International Journal of Science and Research (IJSR) \\ ISSN (Online): 2319-7064 \\ Index Copernicus Value (2013): 6.14 | Impact Factor (2014): 5.611}

Definition of the femur position

Based on our preliminary three-dimensional measurements, at least $95 \%$ of 52 patients with osteoarthritis before THA needed correction of the angle, on plain CT, to the retrocondylar plane from $-10^{\circ}$ to $+10^{\circ}$ (average, $-2.7 \pm 2.9^{\circ}$; a negative value represents extension) for flexion and extension, from $-10^{\circ}$ to $+10^{\circ}$ (average, $-2.2 \pm 3.6^{\circ}$; a negative value represents adduction) for abduction and adduction, and from $-20^{\circ}$ to $+20^{\circ}$ (average, $-10.3 \pm 6.6^{\circ}$; a negative value represents internal rotation) for external and internal rotation of the femur.

Accordingly, the flexion angle was categorized as follows: $-10^{\circ},-5^{\circ},-3^{\circ}, 0^{\circ}$ (parallel to the vertical line), $+5^{\circ}$, and $+10^{\circ}$. Thereafter, abduction was assigned to each femoral model corresponding to each of the 6 different flexion angles according to the following 6 categories: $-10^{\circ},-5^{\circ}, 0,+2^{\circ},+5^{\circ}$, and $+10^{\circ}$. Furthermore, rotation of the femur was assigned to each femoral model corresponding to each of the $36(6 \times 6)$ different angles, according to the following 5 categories: $-20^{\circ}$, $-10^{\circ}, 0,+10^{\circ}$, and $+20^{\circ}$ (Figure 1). Thus, we established 180 $(6 \times 6 \times 5)$ three-dimensional positional conditions. Consequently, we created 1720 (9 morphological models $\times$ 180 positional conditions) three-dimensional femoral models.

We compared the differences between true value of FNA, which was relative to the retrocondylar plane, and those from each three-dimensional femoral model. Moreover, we evaluated certain parameters, including the morphological and positional factors that affected the measured values.

Table 1: FNA values in cases with a femur neck shaft angle of $110^{\circ}$

\begin{tabular}{|c|c|c|c|c|c|}
\hline $\begin{array}{l}\text { Defined } \\
\text { FNA value }\end{array}$ & $\begin{array}{l}\text { FNA value with the femur at } 3^{\circ} \\
\text { of extenaion, } 2^{\circ} \text { of adduction, } \\
\text { and } 10^{\circ} \text { of internal rotation }\end{array}$ & $\begin{array}{c}\text { Maximum } \\
\text { value* }\end{array}$ & $\begin{array}{l}\text { Minimum } \\
\text { value }\end{array}$ & $\begin{array}{l}\text { Diacrepancy between the } \\
\text { maximum value and } \\
\text { minimum value }\end{array}$ & $\left.\begin{array}{l}\text { Extenaion } \\
\text { Adduction } \\
\text { External rotation }\end{array}\right\} \begin{array}{l}\text { Change in } \\
\text { FNA at each } \\
\text { degree } t\end{array}$ \\
\hline 10 & 11.1 & 14.4 & 6.0 & 8.4 & $\begin{array}{c}+0.34 \\
+0.05 \\
-0.001 \text { to }+0.03\end{array}$ \\
\hline 20 & 20.9 & 24.1 & 15.6 & 8.5 & $\begin{array}{c}+0.30 \\
+0.10 \\
-0.001 \text { to }+0.03\end{array}$ \\
\hline 30 & 30.7 & 33.9 & 25.3 & 8.6 & $\begin{array}{c}+0.27 \\
+0.15 \\
-0.001 \text { to }+0.03\end{array}$ \\
\hline
\end{tabular}

The values in the table are presented as degrees. FNA: femoral neck anteversion, *FNA in cases where the femur was at $10^{\circ}$ of extension, $10^{\circ}$ of adduction, and $20^{\circ}$ of external rotation, **FNA when the femur was at $10^{\circ}$ of flexion, $10^{\circ}$ of abduction, and $20^{\circ}$ of external rotation, $\dagger$ : approximate value

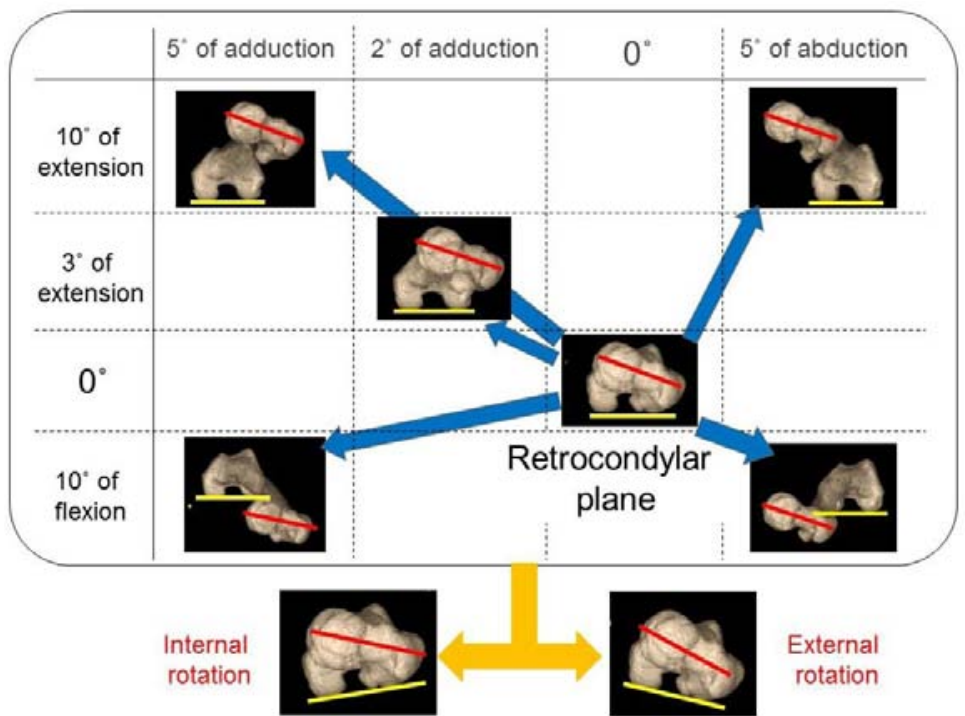

Figure 1: Definition of positional condition of the femur

The retrochondylar plane represents $0^{\circ}$ of flexion, abduction, and external rotation. 


\section{International Journal of Science and Research (IJSR) \\ ISSN (Online): 2319-7064 \\ Index Copernicus Value (2013): 6.14 | Impact Factor (2014): 5.611}

\section{Results}

We observed that in cases where the neck shaft angle was larger, the measured FNA values tended to increase with an increase in the degree of extension and adduction. In contrast, in cases where the neck shaft angle was fixed, the FNA value was smaller, but the measured FNA value tended to increase with an increase in the degree of extension and adduction (Tables 1-3). The measured FNA values increased according to the degree of extension and adduction but decreased according to the degree of flexion and abduction. In cases where the femur was adducted, the measured FNA values decreased according to the degree of internal rotation.

Table 2: FNA values in cases with a femur neck shaft angle of $125^{\circ}$

\begin{tabular}{|c|c|c|c|c|c|}
\hline $\begin{array}{l}\text { Defined } \\
\text { FNA value }\end{array}$ & $\begin{array}{l}\text { FNA value with the femur at } 3^{\circ} \\
\text { of extenaion, } 2^{\circ} \text { of adduction, } \\
\text { and } 10^{\circ} \text { of internal rotation }\end{array}$ & $\begin{array}{l}\text { Maximum } \\
\text { value* }\end{array}$ & $\begin{array}{l}\text { Minimum } \\
\text { value }\end{array}$ & $\begin{array}{l}\text { Diacrepancy between the } \\
\text { maximum value and } \\
\text { minimum value }\end{array}$ & \begin{tabular}{l|l}
$\begin{array}{l}\text { Extenaion } \\
\text { Adduction } \\
\text { External rotation }\end{array}$ & $\begin{array}{l}\text { Change in } \\
\text { FNA at each } \\
\text { degree } t\end{array}$
\end{tabular} \\
\hline 10 & 11.1 & 14.4 & 6.0 & 8.4 & $\begin{array}{c}+0.34 \\
+0.05 \\
-0.001 \text { to }+0.03\end{array}$ \\
\hline 20 & 20.9 & 24.1 & 15.6 & 8.5 & $\begin{array}{c}+0.30 \\
+0.10 \\
-0.001 \text { to }+0.03\end{array}$ \\
\hline 30 & 30.7 & 33.9 & 25.3 & 8.6 & $\begin{array}{c}+0.27 \\
+0.15 \\
-0.001 \text { to }+0.03\end{array}$ \\
\hline
\end{tabular}

The values in the table are presented as degrees. FNA: femoral neck anteversion, *FNA in cases where the femur was at $10^{\circ}$ of extension, $10^{\circ}$ of adduction, and $20^{\circ}$ of external rotation, **FNA when the femur was at $10^{\circ}$ of flexion, $10^{\circ}$ of abduction, and $20^{\circ}$ of external rotation, $\dagger$ : approximate value

In contrast, in cases where the femur was abducted, the measured FNA values increased according to the degree of internal rotation. Irrespective of the neck shaft angle, the measured FNA value was maximum when the femur was at $10^{\circ}$ of extension, $10^{\circ}$ of adduction, and $20^{\circ}$ of external rotation. In contrast, the measured FNA value was minimum when the femur was at $10^{\circ}$ of flexion, $10^{\circ}$ of abduction, and $20^{\circ}$ of external rotation (Tables 1-3).

When the femur was at $3^{\circ}$ of extension, $2^{\circ}$ of adduction, and $10^{\circ}$ of internal rotation, the average correction needed in the retrocondylar plane on plain CT was $1.8^{\circ}$; the discrepancy ranged from $0.7^{\circ}$ in cases where the neck shaft angle was $110^{\circ}$

Table 3: FNA values in cases with a femur neck shaft angle of $140^{\circ}$

\begin{tabular}{|c|c|c|c|c|c|}
\hline $\begin{array}{l}\text { Defined } \\
\text { FNA value }\end{array}$ & $\begin{array}{l}\text { FNA value with the femur at } 3^{\circ} \\
\text { of extenaicn, } 2^{\circ} \text { of adduction, } \\
\text { and } 10^{\circ} \text { of internal rotation }\end{array}$ & $\begin{array}{c}\text { Maximum } \\
\text { value* }\end{array}$ & $\begin{array}{l}\text { Minimum } \\
\text { value }\end{array}$ & $\begin{array}{l}\text { Diacrepancy between the } \\
\text { maximum value and } \\
\text { minimum value }\end{array}$ & $\left.\begin{array}{l}\text { Extenaion } \\
\text { Adduction } \\
\text { External rotation }\end{array}\right\} \begin{array}{l}\text { Change in } \\
\text { FNA at each } \\
\text { degree } t\end{array}$ \\
\hline 10 & 13.4 & 25.8 & -1.8 & 27.6 & $\begin{array}{c}+1.05 \\
+0.18 \\
-0.003 \text { to }+0.09\end{array}$ \\
\hline 20 & 22.8 & 35.5 & 7.4 & 28.1 & $\begin{array}{c}+1.00 \\
+0.35 \\
-0.003 \text { to }+0.09\end{array}$ \\
\hline 30 & 32.2 & 45.1 & 16.6 & 28.5 & $\begin{array}{c}+0.90 \\
+0.48 \\
-0.003 \text { to }+0.09\end{array}$ \\
\hline
\end{tabular}

The values in the table are presented as degrees. FNA: femoral neck anteversion, *FNA in cases where the femur was at $10^{\circ}$ of extension, $10^{\circ}$ of adduction, and $20^{\circ}$ of external rotation, **FNA when the femur was at $10^{\circ}$ of flexion, $10^{\circ}$ of abduction, and $20^{\circ}$ of external rotation, $\dagger$ : approximate value

and FNA was $30^{\circ}$, to $3.4^{\circ}$ in cases where the neck shaft angle was $140^{\circ}$ and FNA was $10^{\circ}$.
Moreover, the maximum discrepancy between the true value and measured value was $15.8^{\circ}$ in cases where the neck shaft 


\section{International Journal of Science and Research (IJSR) \\ ISSN (Online): 2319-7064}

Index Copernicus Value (2013): 6.14 | Impact Factor (2014): 5.611

angle was $140^{\circ}$ and FNA was $10^{\circ}$, when the femur was at $10^{\circ}$ of flexion, $10^{\circ}$ of abduction, and $20^{\circ}$ of external rotation. The largest difference between the maximum discrepancy and minimum discrepancy was $25.8^{\circ}$ in cases with a fixed neck shaft angle and FNA of $140^{\circ}$ and $30^{\circ}$, respectively, when the femur was at $10^{\circ}$ of extension, $10^{\circ}$ of adduction, and $20^{\circ}$ of external rotation (Tables 1-3).

\section{Discussion}

Based on the current findings, we observed that the average correction needed in the retrocondylar plane on plain CT ranged from $0.7^{\circ}$ to $3.4^{\circ}$, when the femur was at $3^{\circ}$ of extension, $2^{\circ}$ of adduction, and $10^{\circ}$ of internal rotation. Nevertheless, the maximum discrepancy was $28.5^{\circ}$, which is not very small. In addition, we observed that the discrepancy affected the femur position to a greater extent when the neck shaft angle and FNA were larger. Hence, when the femur had a high neck shaft angle (valgus hip) and/or high anteversion, the measured value is likely to have a discrepancy. Furthermore, we noted that when the femur was in the flexed position, the measured value of anteversion tended to decrease. Consequently, the measured FNA value in patients with flexion contracture of the hip due to osteoarthritis may be smaller than the true value. Hence, the discrepancy in the FNA value measured from the $\mathrm{CT}$ axial plane, without any correction according to the retrocondylar plane, should be carefully considered.

This current study has certain limitations. One limitation is that an approximate expression of a linear function was applied to express the increasing values according to the degree of extension, adduction, and external rotation. However, the change in FNA appears to be based on a complex mathematical expression according to a trigonometric function. Hence, the approximate values used in the present study do not exactly represent the change in the measured FNA value. Moreover, the results of the present study were obtained from a computer simulation, and hence, the discrepancy between the value measured from a computer simulation and actual measured value needs to be verified.

\section{Conclusion}

The maximum discrepancy between the true value and the measured FNA value was $15.8^{\circ}$, whereas the largest difference between the maximum discrepancy and minimum discrepancy with a fixed neck shaft angle and FNA was $25.8^{\circ}$. In cases where the femur has a high neck shaft angle (valgus hip) and/or high anteversion, it is likely that the measured value is smaller than the actual value. Hence, it is essential to carefully consider the discrepancy of the measured value when the FNA is measured from the CT axial plane without any correction according to the retrocondylar plane.

\section{References}

[1] Fabry G, MacEwen GD, Shands AR Jr. Torsion of the femur. A follow-up study in normal and abnormal conditions. J. Bone Joint Surg 55-A:1726-1738, 1973.
[2] Sugano N, Noble PC, Kamaric E, et al. A comparison of Alternative methods of measuring femoral anteversion. J Comput Assit Tomogr 22:610-614, 1998.

[3] Nakahara I, Takao M, Sakai T, et al. Gender differences in 3D morphology and bony impingement of human hips. J Orthop Res 29:333-339, 2011.

[4] Kingsley PC, Olmsted KL. A study to determine the angle of anteversion of the neck of the femur. J Bone Joint Surg 30-A:745-751, 1948.

[5] Imai $\mathrm{N}$, Ito $\mathrm{T}$, Takahashi $\mathrm{Y}$, et al. In vivo relationship between the clinical epicondylar axis and the anterior pelvic plane in normal subjects. J Biomed Sci Engineer 6:863-868, 2013.

[6] Noble PC, Sugano N, Kamaric E, et al. The three-dimensional shape of the dysplastic femur. Clin Orthop Relat Res 417:27-40, 2003.

[7] Bedi A, Dolan M, Leunig M, et al. Static amd dynamic mechanical causes of hip pain. Arthroscopy 27:235-251, 2011.

[8] Hertsroni I, Torre KD, Duck G, et al. Sex differences of hip morphology in young adult with hip pain and labral tears. Arthroscopy 29:54-63, 2013.

[9] Nakashima Y, Hirata M, Akiyama M, et al. Combined anteversion technique reduced the dislocation in cementless total hip arthroplasty. Int Orthop 38:27-32, 2014.

[10] Ariumi A, Sato T, Kobayashi K, et al. Three-dimensional lower extremity alignment in the weight-bearing standing position in healthy elderly subjects. J Orthop Sci 15:64-70, 2010.

[11] Kobayashi K, SakamotoM, Tanabe Y, et al. Automated image registration for assessing threedimensional alignment of entire lower extremity and implant position using bi-plane radiography. J Biomech 42:2818-2822, 2009.

[12] Sato T, Koga Y, Omori G. Three-dimensional lower extremity alignment assessment system: application to evaluation of component position after total knee arthroplasty. J Arthroplasty 19:620-628, 2004.

[13]Faulkner KG, Cummings SR, Black D, et al. Simple measurement of femoral geometry predicts hip fracture: The study of osteoporotic fractures. J Bone Joint Min Res 8:1211-1217, 1993.14) Merle C, Waldstein W, Gregory JS, et al. How many different type of femora are there in primary hip osteoarthritis ? An active shape modeling study. J Orthop Res :413-422, 2014

\section{Author Profile}

Norio Imai, MD., PhD. is Associate Professor of the Division of Comprehensive Geriatrics in Community, Niigata University Graduate School Medical and Dental Science, Niigata, Japan

Dai Miyasaka, MD., PhD. is Assistant Professor of the Division of Orthopaedic Surgery, Niigata University Graduate School Medical and Dental Science, Niigata, Japan

Shinya Ibuchi, MD. is Medical staff of the Division of Orthopaedic Surgery, Niigata University Graduate School Medical and Dental Science, Niigata, Japan 
Hayato Suzuki, MD. is Medical staff of the Division of Orthopaedic Surgery, Niigata University Graduate School Medical and Dental Science, Niigata, Japan

Ken Suda, MD. is Medical staff of the Division of Orthopaedic Surgery, Niigata University Graduate School Medical and Dental Science, Niigata, Japan

Naoto Endo, MD., PhD. is Professor of the Division of Orthopaedic Surgery, Niigata University Graduate School Medical and Dental Science, Niigata, Japan 